\title{
International Collaborations: Inspiring Active Learning in Higher Education
}

\author{
Caroline Ferguson ${ }^{1}$, Robert Hickey ${ }^{2}$, Shaun Ferns ${ }^{2}$, Robert Savelle ${ }^{3}$ \\ ${ }^{1}$ Ontario Tech University, Canada \\ ${ }^{2}$ Technological University Dublin, Ireland \\ ${ }^{3}$ Durham College, Canada
}

\begin{abstract}
International collaborations can present various challenges; however, with strong leadership and support, as well as through leveraging a variety of online collaborative tools, the results can be great. In this paper, we discuss the process involved in the design, development, and utilization of an openly available active learning handbook that was created by colleagues at three institutions: one in Dublin, Ireland and two in Oshawa, Canada. We discuss the journey that inspired this collaborative project and address some of the unique issues around post conference collaborations. To conclude, we highlight some applications of the handbook across our institutions and beyond.
\end{abstract}

\section{Introduction}

Learner-centered approaches in education have become more commonplace as learning material becomes more readily available [1]. A variety of active learning strategies may be used in class in order to provide students with an opportunity to engage in their own learning and "do" rather than passively receive information from their instructor. Active learning strategies were popularized back in 1991 by Bonwell and Eison, who argued that active learning promotes higher order thinking and encourages analysis, synthesis, and evaluation [2].

The authors of this paper have transitioned through a variety of teaching approaches throughout their time as educators. While they teach in very distinct disciplines, they share a common practice: they have all moved away from a more traditional didactic approach to a learner-centered approach utilizing active learning strategies. Having had so much success in the classroom using these strategies, they felt a desire to share them with the broader educational community by developing an open education resource entitled Active Learning Strategies for Higher Education, The Practical Handbook [4]. This paper describes the process involved in the international collaboration that led to the development of the handbook and highlights how it is being used to inform those involved in the teaching and learning community internationally. Interestingly, the underlying principles that promote success in the classroom and are highlighted in the Active Learning Strategies Handbook formed the basis for the international collaborations that led to its successful completion.

\section{Background}

This section will outline in chronological order how the authors" "active learning" teaching practice evolved over a number of years, eventually becoming common practice in their everyday classrooms.

\subsection{Introducing active learning strategies into the classroom}

The teaching and training of tradespeople or craft workers has traditionally taken place in the workplace [5]. This was considered best practice as it allowed for the development of practical psychomotor skills through the use of demonstrations, practice, and rote learning [6]. In contrast, the theory side of teaching craft workers was typically taught in a more formal educational setting, where a lecturer would deliver content, and learners would passively receive information. Oftentimes, this method of teaching led to lack of student engagement and increased absenteeism from these theory sessions throughout the semester, driving a need to explore alternative teaching methods [7]. For this reason, it was decided to try to introduce active learning strategies into a Construction Craft Worker Apprenticeship program in 2009 (see Figure 1) at the Technological University of Dublin (TU Dublin), formerly the Institute of Technology Blanchardstown Dublin (ITB).

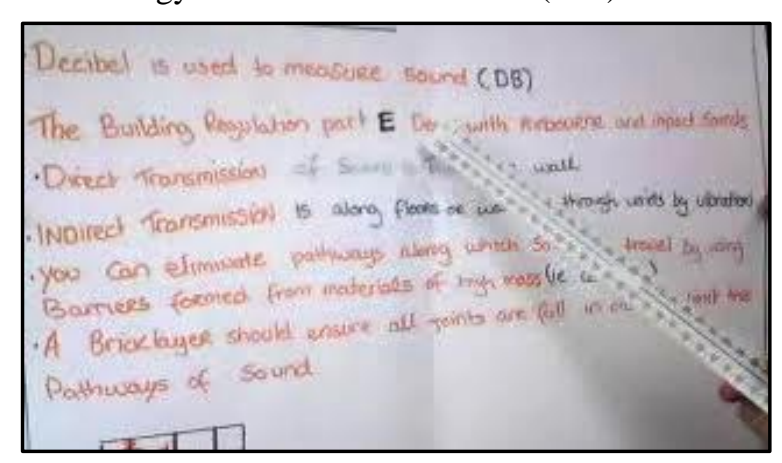

Figure 1: Student group poster presentation, 2nd year

Apprentice Brick \& Stone Layers (Hickey 2009)

https://www.youtube.com/watch?v=Px8WW5gWay8 $\&$ feature=youtu.be 
Initially, well established group and team strategies were incorporated such as Think, Pair, Share [8] and poster presentations. These strategies proved so successful in energizing class discussions and improving attendance while also being very effective for learning, that it was decided to expand their use. As the variety of active learning strategies expanded, so did their use across other programs within the Engineering department at TU Dublin. Active learning strategies were later incorporated into the Bachelor of Science program in Horticulture [9], as well as the Bachelor of Science program in Sustainable \& Electrical Control Technology [10] [11] [12] with great success.

\subsection{QualiBuild Train the Trainer program}

In November 2013, based on their previous development and application of active learning for construction and engineering students, two of the authors of this paper were tasked with the creation of a Train the Trainers (TtT) program for third level educators involved in the delivery of training for construction workers. This program was a key component of the Intelligent Energy Europe Programme QualiBuild project which was developed in response to a series of directives to promote quality energy-efficient buildings throughout Europe.

Due to the limited nature of the face-to-face time available for delivering this $\mathrm{TtT}$ course, an active learning approach was adopted for the project, with a learner centered focus. In order to make time for active learning in the classroom, a flipped learning model was developed whereby learners reviewed course content in customized learner manuals (see Figure 2) prior to face-to-face workshops which ran over two days per module.

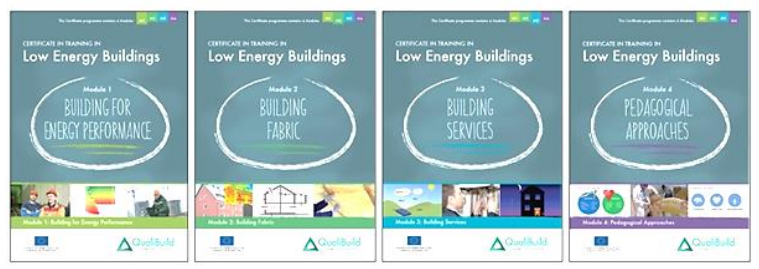

Figure 2: QualiBuild learner manuals (2015) https://ec.europa.eu/energy/intelligent/projects/en/pr ojects/build-skills-qualibuild

The modules were designed to up-skill trainers of those involved in construction who were in employment. For the most part, these trainers were accustomed to using traditional teaching methods where students would passively receive information in a lecture-style setting. This presented a challenge in that learners have pre-acquired beliefs and value systems which often leave them resistant to change. For this reason, one of the key learning objectives of the program was to promote attitudinal change, thereby allowing for perspective transformation [13]. Thus, active learning strategies that had been previously shown to promote attitudinal change were incorporated into the program [14].

\subsection{Active learning strategies based on Direct Attention Thinking Tools}

A series of active learning strategies, founded on the work of De Bono [3], were incorporated in the QualiBuild TtT program. In De Bono's thinking system called The Power of Perception, he introduces a variety of Direct Attention Thinking Tools (DATTs), which are shown in Table 1 below. These tools provide learners the opportunity for encouragement through feedback, therefore promoting learner confidence.

Table 1: List of the ten direct attention thinking tools developed by De Bono (1993)

\begin{tabular}{|c|c|}
\hline \multicolumn{2}{|c|}{ Direct Attention Thinking Tools } \\
\hline $\begin{array}{l}\text { C \& S - Consequence } \\
\text { \& Sequel }\end{array}$ & $\begin{array}{l}\text { PMI - Plus, Minus, } \\
\text { Interesting points }\end{array}$ \\
\hline $\begin{array}{l}\text { RAD - Recognize, } \\
\text { Analyze \& Divide }\end{array}$ & $\begin{array}{l}\text { CAF - Consider All } \\
\text { Factors }\end{array}$ \\
\hline $\begin{array}{l}\text { OPV - Other People's } \\
\text { Views }\end{array}$ & $\begin{array}{l}\text { APC - Alternatives, } \\
\text { Possibilities \& Choices }\end{array}$ \\
\hline $\begin{array}{l}\text { FIP - First Important } \\
\text { Priorities }\end{array}$ & $\begin{array}{l}\text { KVI - Key Values } \\
\text { Involved }\end{array}$ \\
\hline $\begin{array}{l}\text { AGO - Aims, Goals \& } \\
\text { Objectives }\end{array}$ & $\begin{array}{l}\text { DOCA - Decisions, } \\
\text { Outcomes, Channels, } \\
\text { Actions }\end{array}$ \\
\hline
\end{tabular}

DATTs were designed to be utilized in any situation in order to encourage deep thought about a particular concept or topic. Although not specifically designed to be used in a formal education setting, these tools can be utilized as a series of active learning strategies. Of these ten DATTs, the Pluses, Minuses, Interesting Points (PMI) tool was largely incorporated into the QualiBuild TtT program as an active learning strategy (see Figure 3). In this strategy, learners are asked to individually list the pluses, minuses, and interesting points about a particular teaching-related topic.

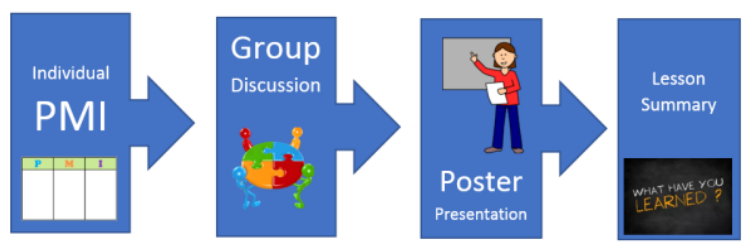

Figure 3: PMI active learning strategy sequence

Learners were then divided into groups of four and given an opportunity to discuss and share their PMI results. Each group was then provided with poster 
paper and a selection of colored markers and tasked with creating a poster that represents the main ideas from their collective results. A few sample PMI posters is shown in Figure 4 below.

Each group is asked to then present their completed poster to the whole class with a question and answer session following each presentation. This allowed any knowledge gaps to be identified and addressed, as well as promoted problem solving, lateral and critical thinking, complex analysis and group work.

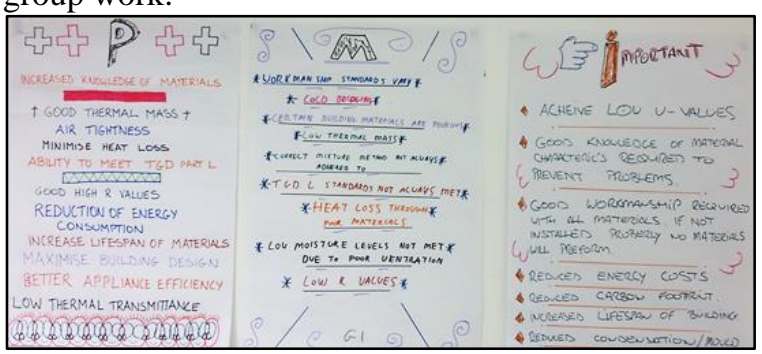

Figure 4: PMI group poster for class presentation

\section{Workshop delivery post QualiBuild}

The continued success and effectiveness of the active learning strategies employed during the QualiBuild pilot project along with the authors' passion for teaching and learning was the driving force behind continuing to deliver TtT workshops. To date, a number of internal training sessions on active learning within TU Dublin have been delivered since 2016.

The objectives of the active learning strategies workshops delivered are for lecturers to: 1) develop an understanding about what active learning is, 2) engage in a community of practice using a social constructivist approach, 3) participate in active learning strategies and develop an appreciation for their effectiveness for both student and instructor, and 4) feel better equipped to employ active learning strategies in their own classes.

\section{HEIT, CHERPP and the practical handbook series}

During the Higher Education in Transformation Conference (HEIT) 2016, which was held at Ontario Tech University in Oshawa, Canada, there were several highly energized debates and discussions around active learning amongst the attendees and contributors. Many were interested in learning how lecturers can implement active learning into their daily teaching practice. As a result of these discussions, four lecturers from TU Dublin decided it would be a good idea to develop a series of instructional documents on this topic, based on their own experience of using active learning in their own classes.
At the conclusion of the HEIT 2016 conference, a Memorandum of Understanding was signed to establish an international collaborative research group named the Centre of Higher Education Research Policy and Practice (CHERPP). This partnership included Ontario Tech University, Durham College, and TU Dublin.

At the first CHERPP meeting, which took place in Canada in June 2018, a series of workshops were delivered with the aim of creating opportunities for collaboration between institutional partners. These were delivered with the support of academic institutions in Canada and Ireland as well as the Government of Ireland Academic Mobility fund and the Higher Education Authority. Two of the TU Dublin staff, who were working on instructional documents in adopting active learning strategies, presented their work with a proposal for the creation of a collaborative active learning handbook that demonstrated the value of active learning strategies in a number of disciplines and contexts.

At the conclusion of these workshops it was agreed that the first project for CHERPP would be the initiation of The Practical Handbook series, a set of step-by-step practical guides for practitioners in higher education. The first handbook, "Active Learning Strategies for Higher Education" was developed and published in January 2019 [4]. This book was based on sound methodologies that a practitioner could easily deploy, comprised of simple step-by-step guides for each activity that educators and their students can embrace. This student-centered pedagogical approach encourages the instructor to take on a facilitator role, thereby allowing learners to build their understanding while also taking responsibility for their own learning. This active, inquiry-based approach is at the heart of what Durham College, Ontario Tech University, and TU Dublin endeavor to provide to students. The handbook demonstrates how the strategies can be applied to diverse problems and contexts within their educational journey and across disciplines. It also provides learners with a framework to utilize when working on problems that they will encounter within the workplace.

\section{International collaborations}

Teamwork and collaboration can present a variety of challenges, especially when members live and work on opposite sides of the world. Figure 5 shows eight of the ten members; although all ten contributors were never able to be physically present in one place at the same time, this did not stop the team from achieving great things together. 


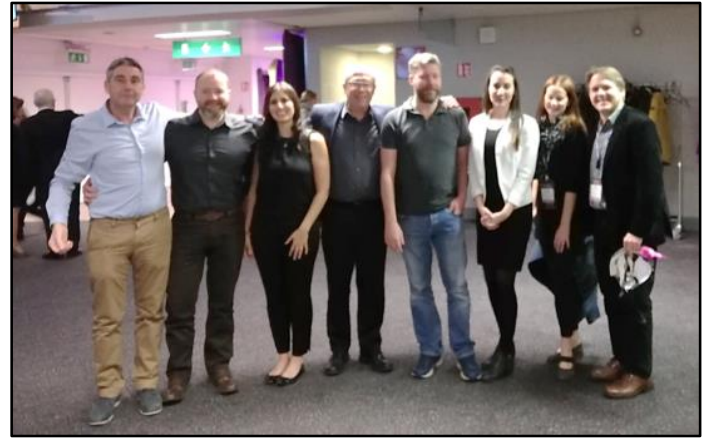

Figure 5: Eight of the ten contributors

The formation of this particular inter-institutional collaboration had no formal planning. As part of CHERPP, a group of approximately 20 postsecondary educators from three Irish institutions (subsequently merged into a single institution - TU Dublin) attended a series of international collaborative workshops in June 2018 at Ontario Tech University in Oshawa Canada, which included faculty and staff from Ontario Tech University and Durham College. All attended on a voluntary basis, as it was not part of their contractual or day to day duties. Throughout the 3-day collaborative workshop, various inter-institutional groups were formed to brainstorm ideas as to potential working collaborations. Many of these groups created ideas for interesting and useful academic projects. Our particular collaboration was fortunate enough to be the first in producing something tangible from our project idea, a practical interdisciplinary publication.

Our group was fortunate, as the seeds of this project were planted prior to the 3 day workshop in June 2018, as two university lecturers in the halls and coffee shops of TU Dublin decided it was time to expand their educational research interests and writing beyond just academic conferences and workshops. However, the project took on a life of its own once TU Dublin, Ontario Tech University, and Durham College professors and lecturers were able to truly connect and flesh out ideas for what would in a short time become the Active Learning Strategies for Higher Education handbook.

From an academic position, a collaboration has been described as a "mutually beneficial and welldefined relationship entered into by two or more organizations to achieve common goals" [15]. The success of this specific collaboration goes beyond this accepted definition, however, as "common goals" was extended to include "for the benefit of students and their learning". The team's passion for teaching and learning and their collective belief that the student needs to be placed at the center of their practice was the common theme that forged them into one group. Indeed, the bulk of this project was created not only to share their own practices, but to learn from others from different disciplines, different learning environments and different cultures.
Another point of note is the methods by which much of this project came into being. While the organization of the 3-day collaborative workshop was done at an institutional level, the connections and eventual commitments made throughout this time together tended to go beyond the structure of the workshop itself. It is acknowledged that successful collaborations often go beyond the formal settings of a workshop or conference, and that the social element at such events "can lead to affirming shared understanding, new relationships, and even new major collaborations." [16]. Human interaction, mutual participation, collegial ties, equality, and one focused goal are all traits of an effective active learning environment. Outside of the workshops, during the planned social events and spontaneous social gatherings, participants and colleagues got to know one another on a more personal basis. This allowed group members an opportunity to highlight their professional interests and express their personal ideas in smaller more intimate groups.

As with many post-conferences and workshops, however, the excitement and enthusiasm of new ideas and connections often wanes, and many planned collaborations fail to materialize. Indeed, at this series of workshops, numerous stimulating ideas never went beyond the flipchart. The fact that this project continued to flourish can be credited not only to interdisciplinary interests and newformed personal ties, but also to the efforts made to follow up on initial commitments.

Communication of course plays a vital role in the quality of academic collaborations, particularly when they occur in different institutions and countries. The level of engagement by participants during the development of the active learning handbook remained strong in part because of the use of Slack, Google Docs, and other forms of virtual communication. Regular updates every two weeks via email from the project lead kept everyone up to date with the project's progress, deadlines and open calls for suggestions, including regular peer feedback between the group members, infused a feeling of inclusivity.

Of equal importance, especially with such a large team of collaborators, was the quality of the communication. With the potential for various levels of conflict during collaborative exercises with many interdisciplinary academics involved, it has been suggested that a mediator be present to guide the research process [17]. In this case, while no mediator was officially nominated, the project lead was able to use his technical skills and personal encouragement to ensure the process went as efficiently as possible. Indeed, all ideas were encouraged, regardless of how well or not they fit into the broader vision or specific template for this particular project. Drafts were placed on Google Docs and shared with group members, who were all initially joint editors. All contributors were 
asked to provide as much detailed feedback as possible for each chapter drafted. Eventually one person had to take on the responsibility of editing the final drafts before multiple proofreads were carried out. Perhaps unsurprisingly given the underlying theme of the eventual publication, the entire process was truly a practice in active learning, with group work, collaboration and social constructivism at its center.

\section{Active learning strategies handbook in action}

The subsequent six months since its publication [4] there have been a number of training sessions and workshops delivered based on the strategies contained within the handbook. Participants actively engaged with both their colleagues and the facilitators to ensure as much personal interaction as possible, for when it comes to learning, action without human interaction is just not as effective.

\subsection{Active learning workshops offered at Ontario Tech University}

The Teaching and Learning Centre at Ontario Tech University facilitates a variety of workshops for all members of the teaching community, including faculty, staff, and teaching assistants. In February 2019, an active learning strategies workshop was developed based on seven of the ten strategies highlighted in the handbook; participants had the opportunity to engage with each of these strategies as both a learner and as a facilitator, and discuss their strengths, limitations, and applications in higher education.

A similar workshop was delivered again during the spring 2019 term. The Teaching and Learning Center plans to continue to offer this workshop multiple times throughout the year to the Ontario Tech University teaching community, as well as a condensed version during orientation sessions for new faculty and staff.

\subsection{Active learning workshops offered at TU Dublin}

To date, staff at TU Dublin have facilitated a number of departmental training days for the School of Humanities in 2018 and the School of Business in 2019, focusing on implementing active learning strategies within course and program delivery.

The main strategy utilized for delivering these training days was the PMI. This straightforward activity can be used with any size group (from six to sixty) and over a variety of timespans (thirty minutes to three hours).
After the successful design and delivery of the workshop developed by the Teaching and Learning Centre at Ontario Tech University (based on seven strategies from the handbook), staff at TU Dublin have applied for funding from the National Forum for the Enhancement of Teaching and Learning, to run this same workshop in Ireland in December 2019. Attendance at this workshop will be open to all postsecondary educators in Ireland.

\subsection{Active learning workshops offered internationally}

As part of the dissemination plan for the Active Learning Handbook, contributors submitted workshop proposals to a number of conferences.

In October 2018 at the international Universal Design \& Higher Education in Transformation Congress, held in Dublin Castle Ireland, the Irish contingent of this group presented a workshop titled "Practical Strategies for Higher Education" [19].

Following on from this in June 2019 a similar active learning workshop was delivered at the Canadian International Conference on Education, at the University of Toronto, Mississauga (see Figure 6). This "Active Learning Student-centered Workshop" [20] was delivered by a larger Canadian and Irish contingent (the four authors of this paper).

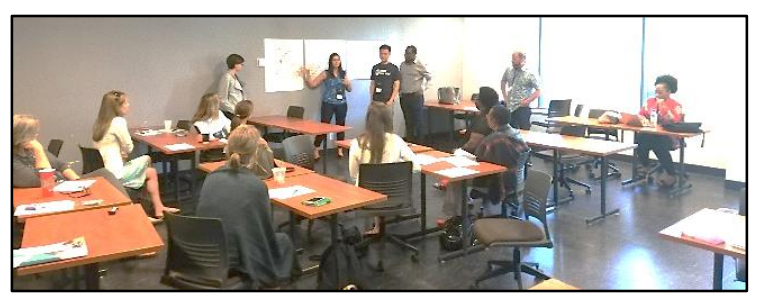

Figure 6: Workshop delivered at CICE June 2019

In addition, as part of the "Enhancing Student Learning Through Innovative Scholarship: Active Learning for All Conference (ESLTIS)" in July 2019 at Edinburgh Napier University, Scotland, a workshop called "How to Implement Active Learning in Your Classroom" [21] was delivered. Again, this was based on strategies presented in the handbook.

\section{Conclusion}

International collaborations bring diverse perspectives in order to achieve a common goal. In the case of this project, these collaborations resulted in the development and publication of an open educational resource to promote active learning in higher education. Through leveraging each member's own experiences in the classroom, the team was able to apply the fundamentals of active learning in order to manage their very own international collaboration. This project was based on the same principles that 
allow students to thrive in an active classroom: Developing strong relationships and personal connections, creating a safe space where collaboration and peer feedback is encouraged, and setting a common goal to create something that is tangible and actively "do" rather than passively receive information. The critical thinking, analytical, and communication skills that are promoted in an active classroom are essential skills, both for today's students, as well as for educators alike.

\section{References}

[1] Owende, P. Lavelle, D. \& Ferns, S. (2007); Flexible Delivery of Mechatronic Programmes A Review of concepts for Learner-Centred Approach

[2] Bonwell, Charles C. and James A. Eison. (1991) 'Active Learning; Creating Excitement in the Classroom' ASHEERIC Higher Education Report No. 1. Washington, D.C.: The George Washington University, School of Education and Human Development. https://files.eric.ed. gov/fulltext/ED336049.pdf

[3] De Bono, E. (1993) Serious Creativity: Using the Power of Lateral Thinking to Create New Ideas. Harper Business.

[4] Ferns et al. (2019) Active Learning Strategies for Higher Education. Centre for Higher Education Research, Policy, and Practice. CHERPP. ISBN:1900454661

[5] Clarke, L. and Winch, C. (2004) 'Apprenticeship and applied theoretical knowledge'. Educational philosophy and theory, 36 (5), pp.509-521.

[6] Toohey, S. (1999) Designing courses for higher education. Buckingham: SRHE and Open University Press.

[7] McCarthy, J.P, and Anderson, L. (2000) 'Active learning techniques versus traditional teaching styles: Two experiments from history and political science.' Innovative higher education 24 (4), pp. 279-294.

[8] Lyman, F. (1981) 'The Responsive Classroom Discussion: The Inclusion of All Students'. Mainstreaming Digest.

[9] Hickey, R. (2011) '. Creation of Learning Objects for a module in (Hard Landscape Construction)' Second annual report on teaching and learning innovations. ITB, pp. 27-28. https://www.itb.ie/AboutITB/QualityAssuranceReports/Te aching\%20and\%20Learning\%20Innovations\%202011.pdf

[10] Hickey, R. (2012) 'Using Pre-Recorded Lessons to Free up Class Time for Activity Based Learning through Lateral Thinking' Unpublished poster presentation at: 5th Annual Learning Innovation Network Conference, October 11-12, Dublin, Ashling Hotel. http://www.lecturer101.com/rhickeylin2012.pdf.

[11] Hickey, R. (2013) 'Using Flipped Learning to allow collaboration and constructivism in the class for a module in sustainable technology' Third Annual Report on Teaching and Learning Innovation. ITB, pp. 63-66.
https://www.itb.ie/AboutITB/QualityAssuranceReports/Te aching\%20and\%20Learning\%20Innovations\%202013.pdf

[12] Hickey, R. (2015) 'Using Flipped Learning. A Case Study' Unpublished poster presentation at: 15th Annual Showcase of Learning and Teaching Innovations. Reprogramming Higher Education to Enhance the Learning Experience, January 14, Dublin, DIT Aungier Street. http://www.lecturer101.com/flippedlearning2015.pdf

[13] Kaplowitz, S. A. and Fin, E. L. (1982) 'Attitude Change and Attitudinal Trajectories: A Dynamic Multidimensional Theory' Annals of the International Communication Association, vol. 6, pp. 364-394. doi:10.1080/23808985.1982.11678504

[14] Keyes, M., Hickey, R., Ferns, S., Hynes, D., Ryan, R. and Cussen, J. (2016) 'QualiBuild Train the Trainer Lessons Learned from the Development of a Program for Training Trainers of Construction Workers' Higher Education in Transformation Conference (HEIT), Oshawa, Canada. https://arrow.dit.ie/heit167/1/

[15] Mattessich, P. W. and Monsey, B. R. (1992) 'Collaboration: what makes it work. A review of research literature on factors influencing successful collaboration' Amherst H. Wilder Foundation, 919 Lafond, St. Paul, MN 55104.

[16] Bailey J.S. and Alexander M.C. (2017) 'Getting the Most Out of Academic Conference Attendance: Five Key Strategies' International Journal of Qualitative Methods $\begin{array}{llll}\text { Volume } & 16 . & \text { pp. } & 1-2 .\end{array}$ https://journals.sagepub.com/doi/pdf/10.1177/16094 06917740441

[17] Gunawardena, S., Weber, R. and Agosto, D. E. (2010) 'Finding that special someone: Interdisciplinary collaboration in an academic context' Journal of Education for Library and Information Science. vol. 51. (5) pp. 210221

[18] Ferns, S., Hickey, R., Keys, M., Ryan, R., Cussen, J. and Hynes, D. (2016) 'Active Learning Student-Centered Workshop' Higher Education in Transformation Conference (HEIT), Oshawa, Canada. http://www.highereducationintransformation.com/co ntentfiles/heit-program-final.pdf

[19] Hickey, R., Ferns, S., Keys, M., Smith, J. and Ryan, R. (2018) 'Practical Strategies for Higher Education' Workshop. Universal Design \& Higher Education in Transformation Congress, Dublin Castle, Ireland. pp. 37. https://docs.wixstatic.com/ugd/c416fd_ac75eb0ba8a34508 bd90078fb5e74fa4.pdf

[20] Hickey, R. \& Ferns, S. (2019) 'How to Implement Active Learning in your Classroom' Workshop. Enhancing Student Learning Through Innovative Scholarship: Active Learning for All Conference (ESLTIS). Edinburgh Napier University, Scotland. Session 6C.http://community.dur.ac. uk/s.j.nolan/Abstracts_2019.pdf 
International Journal for Cross-Disciplinary Subjects in Education (IJCDSE), Volume 10, Issue 3, September 2019

[21] Hickey, R., Ferns, S., Ferguson, C. and Savelle, R. (2019) 'Active Learning Student-centered Workshop' Canadian International Conference on Education (CICE), Toronto, Canada. 